\title{
Impact of Procedural Justice on Turnover Intention with Mediating Effect of Trust
}

\author{
Maryam Tajammal* \\ Capital University of Science and Technology, Islamabad, Pakistan
}

\begin{abstract}
This research conducted a survey to examine the impact of procedural justice on turnover intention through mediation of organizational trust. The study is based on a sample of 141 faculty members of the public and private sector universities of twin cities of Pakistan who completed structured questionnaires for each variable. Data were analyzed using SPSS and results revealed that procedural justice has negative and significant effect on turnover intentions of employees. Furthermore, organizational trust successfully mediates the relationship between Procedural justice and Turnover intention. We conclude study, discuss theoretical implications and also provide future recommendations.
\end{abstract}

\section{Introduction}

In the present time, employees turnover is a global phenomenon. It has become a serious and complicated issue as it is a major problem pervasive in all kinds of organizations in the world. It is difficult for the organizations to sustain success amidst such a problem. Organizations spend a lot in hiring, training, and retaining employees. After huge investment it is painful and costly for them to have high turnover (Khattak, 2010).

Developing countries like Pakistan are also facing this problem in all sectors especially education sector. Annually, huge number of teachers quit teaching and others transfer to other institution. (Ingersoll, 2001) in recent years has come forward with support and confirmation that students and schools are affected by teachers turnover. Although it is a severe issue in Asia but unfortunately, studies are short to inspect turnover intention and studies which consist of wide ranged variable sets (Khatri et al., 2001)

According to Hopkins and Weathington (2006) organizations have to invest time and money in replacing those who go away. To control turnover it is important to know about it before it happens actually. The best option for the organizations is to have knowledge about turnover intentions of employees as it is the development of consideration, preparation, and wish for a job quit as it has positive causal relation with actual turnover (Choi, 2006) and generally is the second last stage of deliberate quitting. Ninety three percent empirical studies suggest high correlation of TOI with real quit. Turnover intention is preferred as compared to definite turnover in the studies as T.O makes matters

*Corresponding author.

Email: maryam.hashmi88@gmail.com worse and is difficult to predict as compared to intention (Hemdi and Nasurdin, 2007).

According to Aryee et al. (2002) it is vital to be acquainted with an employees feelings, whether he/she (individually) is treated unfairly in the organization, he may expect that transfer to another department or function or branch of same organization will depart this feeling of unfair treatment. On the other hand, when the climate of organization is unfair or unjust, employees will perceive that transfer to another department, function or branch of the same organization will not improve their position, as it is procedurally unjust climate. Therefore, they will show more intention to quit. Studies show that the relationship between procedural justice and turnover intentions has been mediated by trust perceptions (Hopkins and Weathington, 2006). Similarly, in various studies, procedural justice was found to be positively linked with trust on organization (Hopkins and Weathington, 2006; TZAFRIR et al., 2012). It has also been posited by Gopinath and Becker (2000), that Procedural justice is only one of its kinds, which brought more changes in turnover than other dimensions of justice.

\section{Literature Review}

\subsection{Procedural Justice}

Organizational justice is considered as a perception of the organization. Organizational justice is what is perceived by the employees about whether they are treated fairly or not. So it is a perception about the 
fairness and the equality of the organization and also such perception has very deep effect on the attitudes and behaviours of the employees (Poon, 2012). Organizational justice has many dimensions out of which procedural justice and distributive justice are more important (Lambert et al., 2012). Distributive justice is basically about the perception of the employees of how fair are the outcomes given to them (e.g. pay, status) but procedural justice is perception of the employees of how fair are the methods or ways used to give those outcomes. Procedural justice is defined as the perception about means and processes used for taking decisions in the organization (Colquitt et al., 2001). It is also about employees perception about whether or not the methods or the processes used by the organizations to make decisions are fair (Lambert et al., 2012). Main concern of the study is about procedural justice because employee who perceives himself to be given fair treatment, procedurally, he considers his organization as a whole fair ( $\mathrm{Li}$ and Bagger, 2012). Procedural justice focuses on the organization but distributive justice focuses more on the outcomes (Tulubas and Celep, 2012). If the employees know that the outcomes are not favorable for them then before showing any reaction they would first see the whole process of outcome determination.

\subsection{Procedural Justice and Organizational Trust}

Robinson (1996) defined trust as ones expectations, assumptions, or beliefs about the likelihood that anothers future actions will be beneficial, favorable, or at least not detrimental to ones interest (p. 575).Organizational trust is a psychological implicit relationship between employee and organization and trust lacks when one of them breaks this relation (Hopkins and Weathington, 2006). Trust can be defined as a psychological state comprising the intention to accept vulnerability based upon positive expectations of the intentions or behavior of another (Rousseau et al., 1998). There are some important parts of the definition. Firstly the trust includes risk; secondly, it involves expectations of the truster that the other party would perform behaviors that are desired to the truster. So the trustee must be able to act according to the desires of the truster and must have the willingness to do so. Thirdly, the desired behaviors of the truster must be somewhat important to the trustee. For example if he is expected to work hard the hard work must be associated with some bonus or extra pay. It is considered as multidimensional; consisting of four dimensions of trust, i.e. the competence, openness, concern and reliability (Wong et al., 2012) and multifocal construct such as employees encompass trust towards co-workers, direct boss, and entire organization (Lehmann-Willenbrock et al., 2013).
A study by Tzafrir et al. (2004) showed a significant impact of procedural justice on trust. Zeinabadi and Salehi (2011) investigated two links to predict OCB; one through organizational trust and second through job satisfaction and organizational commitment, based on data from public schools teachers and principals. Procedural justice has impact on trust. But in this study researchers do not apply the target specific and multidimensional approach. In the study of Hubbell and Chory-Assad (2005) who took data from different organizations on the basis of geographic region and revealed that procedural justice is found to be an antecedent of organizational trust as well as managerial trust. On the other hand, distributive justice only has an impact on managerial trust and no impact on interactional justice or trust. SPENCE LASCHINGER et al. (2012) gathered data from three joint ventures of one province of China to inspect the relationships between organizational justice, perceived organizational support, organizational trust and organizational citizenship behavior. Their results showed a significant impact of procedural justice on trust. Similar results were found by Aryee et al. (2002); Hopkins and Weathington (2006); in their respective studies.

H1. Higher the perception of procedural justice, stronger is the trust of employees on the organization.

\subsection{Procedural Justice and Turnover Inten- tion}

Employees withdrawal is a worldwide phenomenon in the current age. According to Currivan (1999), Turnover is a behavior which describes the process of leaving or replacing employees in an organization. It is a behavioral withdrawal reaction (Geurts et al., 1999), a degree of intention to leave. Turnover intention is a known factor for actual turnover of employees. The intension to quit does not always lead to quitting, but chances of quitting are very high turnover intention is viewed as employees having strong willingness to leave their job in which they are working, due to the reason they are not satisfied with the pay procedures, lack of commitment towards organization, have feeling of inequality and so they want to leave.

Employees, who intend to leave the job, may perceive their organizational procedures, rules, policies, methods as unfair to them (Folger and Cropanzano, 1998). Aryee et al. (2002) in their study took full time employees of public sector of India and found that procedural justice negatively affects the turnover intention of employees. Johan et al. (2013) examined in their study the correlation between procedural justice and turnover intention and found significant negative correlation between the two. Çelik et al. (2016); Lin and Chen (2004) also showed same results in their respec- 
tive studies.

H2. Higher Perception of procedural justice, lower is turnover intention of employees.

\subsection{Trust and Turnover Intention}

In previous research it is shown that trust cushions the undesirable and off-putting working actions for example nonattendance and turnover (Hopkins and Weathington, 2006; Way et al., 2007). It can be concluded that the presence of trust within an organization results in motivation which brings positive outcomes like feeling of support from and attachment to the organization and consequently employees would be eager to remain part of the institute, have low intentions to quit. Employees who find alternative job possibilities, are less committed, and have higher turnover intention (Mobley et al., 1979). When workers dont have any trust in organization then they decide to leave (Koslowsky and Caspy, 1991). An employee attitude towards job is very important, it describes his intentions to leave or not. Low affiliation to organization causes leaving desires in employees and directs them to search another job; this creates a sense of confusion in their mind (Mobley et al., 1978). A feeling of trust, affiliation with current job reduces the chances of quitting the job. Aryee et al. (2002) also shows negative relation between trust and turnover intention.

H3. Higher trust in organization, lower is the turnover intention of employees.

\subsection{Organizational Trust as a Mediator}

Some direct relations in previous researches have been eliminated and ensuring the trust mediation between them e.g. the direct relation of Procedural justice to organizational citizenship behavior and Organizational commitment and they found significant indirect effect between procedural justice and OCB and OC and taking trust as an imperative mediator (Hopkins and Weathington, 2006; Zeinabadi and Salehi, 2011). Similarly, when employees perceived organization as procedurally fair, it enhanced their trust on organization and lead to less intention to leave organization. (Aryee et al., 2002) in their study revealed a partial mediation of organizational trust between procedural justice and turnover intention. Hopkins and Weathington (2006) conducted a study among survivors of an organization that had recently completed an organizational downsizing and also found the partial mediation of organizational trust between procedural justice and turnover intention.

H4. The relationship between procedural justice and turnover intention is mediated by organizational trust.

\section{Theoretical framework}

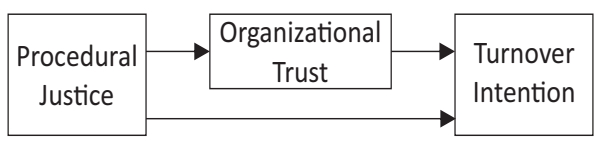

Figure 1: proposed model

\section{Methodology}

\subsection{Sample of study}

The participants are faculty members of the public and private sector universities of twin cities of Pakistan. For this purpose Convenient sampling method was used and questionnaires were distributed in limited universities (PMAS arid agriculture, AIR University, BAHRIA University, NUML, etc). Structured Questionnaires were distributed in different universities and total number of $\mathrm{N}=141$, self administered questionnaires filled by respondents were taken. The $64.5 \%$ respondents were male and remaining $35.5 \%$ were female. Majority respondents $(39.7 \%)$ were lying in the age range of 30-39, followed by $22.0 \%$ between $25-29$ range and $19.9 \%$ between $40-49$ ranges. In marital status $63.8 \%$ were married and $35.5 \%$ single. Majority $(68.8 \%)$ were from private sector and remaining $31.2 \%$ from public sector universities. Maximum respondents job tenure was 3-4 year (33.3\%). Monthly income of majority respondents was between in the range of 4100050000, whereas, $9.9 \%$ respondents did not show their monthly income.

\subsection{Measures}

For uniformity and consistency purpose, we managed all items using a 5-point Likert-type scale ( $1=$ strongly disagree, $5=$ strongly agree). Several scales are modified from their original form.

\subsubsection{Turnover intentions}

A scale for turnover intention was adopted by Aryee et al. (2002). Items included were I often think about quitting my job with my present organization; I will probably look for a new job within the next year.

\subsubsection{Procedural justice}

Procedural Justice Scale was adapted from Moorman (1991). It consists of seven items. This scale shows reliability of .94 in previous study Hopkins and Weathington (2006). Some questions of scale are; my organizations formal procedures are designed to collect accurate information necessary for making decisions; My 
Table 1: Correlation Matrix \& Reliabilities

\begin{tabular}{llccccccc}
\hline & Scale & Mean & SD & Min & Max & $\mathbf{1}$ & $\mathbf{2}$ & $\mathbf{3}$ \\
\hline $\mathbf{1}$ & Procedural Justice & 3.56 & 0.92 & 1 & 5 & $1(.899)$ & & \\
$\mathbf{2}$ & Turnover Intention & 2.42 & 1.15 & 1 & 5 & $-.560^{* *}$ & $1(.878)$ & \\
$\mathbf{3}$ & Organizational justice & 3.71 & 0.81 & 2 & 5 & $.734^{* *}$ & $-.545^{* *}$ & $1(.902)$ \\
\hline$N=141,{ }^{* *} p<.01$ & & & & & & &
\end{tabular}

Table 2: Regression Results

\begin{tabular}{lcccccc}
\hline Predictors & \multicolumn{3}{c}{ Organizational Trust } & \multicolumn{3}{c}{ Turnover Intention } \\
& $\beta$ & $R^{2}$ & $\Delta R^{2}$ & $\beta$ & $R^{2}$ & $\Delta R^{2}$ \\
\hline Procedural justice & $0.650^{* * *}$ & 0.54 & 0.535 & $-.707^{* * *}$ & 0.314 & 0.309 \\
Organizational trust & & & & $-.777^{* * *}$ & 0.297 & 0.292 \\
\hline$N=141,{ }^{* * *} p<0.001,{ }^{*} p<0.05$ & & & & & &
\end{tabular}

organizations formal procedures are designed to provide opportunities to appeal or challenge the decision; My organizations formal procedures are designed to generate standards so that decisions can be made with consistency.

\subsubsection{Organizational trust}

Organizational trust scale was measured with nine items developed by Neininger et al. (2010). 6- Point answering format was converted to 5-point $(1=$ strongly disagree, $5=$ strongly agree) for convenience. Cronbach alpha value for organizational trust was recorded .89 in recent year study (Lehmann-Willenbrock et al., 2013). Sample items for organizational trust were: Information can be shared openly within $X$ (insert name of organization); I feel encouraged to do a good job at $X$; I have positive feelings about the future direction of $X ; X$ offers a supportive work environment; Processes within $X$ are fair, etc.

\section{Results}

Table 1 depicts Mean, Standard Deviation, Range and Alpha Reliability Coefficients of each Measure ( $\mathrm{N}=141)$. According to the above information, the scale of Organizational trust shows highest value of alpha (.902). Whereas, the minimum value of alpha coefficient (.878) was for turnover intention which shows that questionnaires were reliable as they meet the minimum acceptable standard for alpha, which should be at least 0.70 (Nunnally, 1978).

\subsection{Regression}

Table 2 shows the results of regression analysis. Hypotheses were tested through linear regression anal- ysis using SPSS. We do not take control variables in our study as it did not have any significant relation with variables. Mediation analysis is carried by following Baron and Kenny (1986). According to the statistical results, first hypothesis is accepted $(=.650, \mathrm{p}=.000)$ and shows that perception of employees about the means and methods of organization which are used by organization to take decisions about employees, leading to higher the trust level of employees. Second hypothesis tested that when employees found their organization procedurally fair; they have fewer intentions to leave the organization. And statistical analysis supports it (= -.707, $\mathrm{p}=.000$ ). Third hypothesis is also supported in our study which tested $(=-.777, \mathrm{p}=.000)$ that the higher trust in organization, the lower is turnover intention of employees.

Table 3: Regression for Outcomes

\begin{tabular}{lccc}
\hline Predictors & \multicolumn{3}{c}{ Turnover Intention } \\
& $\beta$ & $R^{2}$ & $\Delta R^{2}$ \\
\hline Step 1 & & & \\
Organizational trust & $-.777^{* * *}$ & 0.297 & 0.292 \\
Step 2 & & & \\
Organizational trust & $-.413^{* *}$ & & \\
Procedural justice & $-.438^{* *}$ & 0.353 & 0.344 \\
\hline$N=141^{* * *} p<.001,{ }^{* *} P<.01$ & &
\end{tabular}

Fourth hypothesis tested that organizational trust mediated the relation between procedural justice and turnover intention. It has also been accepted as per the results of regression shown in table 3. As effect of procedural justice on turnover intention $(=-.707$, 
$\mathrm{p}=.000)$ was significantly declined when effect of organizational trust is controlled (from $=-.707, \mathrm{p}=.000$, to $=.438, \mathrm{p}=.001$ ). It shows that organizational trust has partial mediation effect on this relation.

\section{Discussion}

Our findings prove that the higher Perception of procedural justice, the stronger the trust of employees on the organization. Evidences from prior studies (Colquitt and Rodell, 2011; Greenberg, 1987; Pillai et al., 2001) also support it. Our research provides the pragmatic evidence that the trust of employees on the organization has a dominant impact on the organization. Our second hypothesis stated that higher Perception of procedural justice; leads to lower turnover intention of employees. Our findings proved this and it is also consistent with prior studys findings (Aryee et al., 2002; Folger and Cropanzano, 1998). Our third hypothesis is the higher trust in organization; the lower is turnover intention of employees. Our research provides the empirical evidence that the trust on the organization has a dominant impact on the turnover intentions of employees. The study shows that the organizational trust leads to the lowering of intensions among the employees to leave the organization. In previous researches it has demonstrated that more trust stifles undesirable outcomes, i.e. absence and turnover (Way et al., 2007). When we look at the previous studies, the relationship between trust and intension to quit is strongly supported. Fourth hypothesis of our study is the relationship between procedural justice and turnover intention is mediated by organizational trust. In fact, using fair procedures enhances the trust of employees on the organization as result of which they own their organization and subsequently the intensions of the employees to leave the organization are decreased. There is support from previous researches that organizational trust mediates between procedural justice and turnover intention (Hopkins and Weathington, 2006). Fifth hypothesis is the higher Perceived alternative job opportunities, the higher are turnover intention. Our findings strongly proved this hypothesis. Researches of previous studies also show consistent results to this (Hwang, 2006; Rahman et al., 2008).

\subsection{Implications}

This research has implications for organizational policy makers and researchers. It is aimed at improving the effectiveness of the organizations. This study provides more comprehensive understanding about how trust \& justice impact the intentions of employee to leave the organization. Firstly our study tells about the procedural justice and organizational trust which improve the employees job related attitudes and behav- iors.

This research finds the impact of procedural justice and turnover intention, organization trust as a mediator between them. The results show that the fairness perception of procedures, processes and the level of employee trust on the organization affect the employees intentions to leave the organization. So the research also has implications for the social exchange theory. Organizations have impact on motivating the social exchange indicators among employees through building trust among the employees and ensuring the fairness of procedures of making decisions.

The organizational authorities should try to ensure that the procedures of allocating the outcomes to the employees are fair and consistently applied to all employees equally. More specifically organizations can control turnover rate of employees by not just focusing procedural fairness, but also by developing employees trust on the organization. Through this process employees would become more trusted one to the organization and never try to quit.

\subsection{Limitations}

The generalizability of our research is restricted by some limitations. First of all the scales were adapted from the researches which conducted in West used for the research. So such scales would not be very much effective in the Asian conditions. Such measure must be adapted and refined to make them fit to the particular conditions. Secondly, we collected all the data at the same time, while we wanted to see the causal relationships between different variables. So the data collected through cross-sectional method would not be able to confirm such casual relationships, instead a longitudinal research design is needed for confirmation. Thirdly, the data collected for this research can be subjected to common- method bias, because same questionnaires were used to collect all the data. Another important limitation would be that because the data were collected from the universities of Rawalpindi and Islamabad, the effect of gender on variables of our study, was not considered. Similarly, all the data collected from the teachers in the universities of Rawalpindi and Islamabad; there is a need to replicate the results in the corporate sector using the larger samples so that the variables relationship strength may differ with other work settings. Lastly, technique of sampling would be a big question mark to the generalizability of the results. Although, our study gives explanation for causal relationship; it does not recognize correlation relationship.

\subsection{Future recommendations}

Our research gives opportunity for many possibilities in future. Further research should confirm the 
finding of this paper. We have taken procedural justice as an independent variable in our model which is basically concerned with the perception of employees about how fair are the procedures of allocation of outcomes to them. Such perceptions of employees build up trust of employees on the organization and lead to many attitudes. But many questions are still unexplored including what effects, if any, a fair process has on the performance of the employees individually and in team settings also? Can this perception of fairness of procedures be helpful in overcoming the weaknesses present in the employees? To what extent the fairness of procedures lead to the overall effectiveness of the organization?

Along with answering these questions, future research can also focus on other dimensions of justice including interactional and systematic justice which will lead to individual level outcomes and job outcomes (DeConinck and Stilwell, 2004; Sweeney and McFarlin, 1993; Tekleab et al., 2005) it will provide more comprehensive understanding.

Further researches should segregate the results of private and public sector; researchers should investigate how much result is different in both sectors. Comparison of both sectors is recommended in future. We have seen the effect of perception of fairness of procedures in the model of turnover intensions in the education sector. Future researchers can focus on economic sector also. Moreover next studies can make comparison between public sector institutes and private sector institutes. They can investigate that which sector is more procedurally fair and how much results are dissimilar.

\section{References}

Aryee, S., Budhwar, P. S., and Chen, Z. X. (2002). Trust as a mediator of the relationship between organizational justice and work outcomes: Test of a social exchange model. Journal of organizational Behavior, 23(3):267-285.

Baron, R. M. and Kenny, D. A. (1986). The moderatormediator variable distinction in social psychological research: Conceptual, strategic, and statistical considerations. Journal of personality and social psychology, 51(6):1173.

Çelik, D. A., Yeloğlu, H. O., and Yıldırım, O. B. (2016). The moderating role of self efficacy on the perceptions of justice and turnover intentions. Procedia-Social and Behavioral Sciences, 235:392-402.

Choi, K. (2006). A structural relationship analysis of hotel employees' turnover intention. Asia Pacific Journal of Tourism Research, 11(4):321-337.

Colquitt, J. A., Conlon, D. E., Wesson, M. J., Porter, C. O., and
$\mathrm{Ng}$, K. Y. (2001). Justice at the millennium: a meta-analytic review of 25 years of organizational justice research.

Colquitt, J. A. and Rodell, J. B. (2011). Justice, trust, and trustworthiness: A longitudinal analysis integrating three theoretical perspectives. Academy of Management Journal, 54(6):1183-1206.

Currivan, D. B. (1999). The causal order of job satisfaction and organizational commitment in models of employee turnover. Human resource management review, 9(4):495-524.

DeConinck, J. B. and Stilwell, C. D. (2004). Incorporating organizational justice, role states, pay satisfaction and supervisor satisfaction in a model of turnover intentions. Journal of Business Research, 57(3):225-231.

Folger, R. G. and Cropanzano, R. (1998). Organizational justice and human resource management, volume 7 . Sage.

Geurts, S. A., Schaufeli, W. B., and Rutte, C. G. (1999). Absenteeism, turnover intention and inequity in the employment relationship. Work E Stress, 13(3):253-267.

Gopinath, C. and Becker, T. E. (2000). Communication, procedural justice, and employee attitudes: Relationships under conditions of divestiture. Journal of management, 26(1):6383 .

Greenberg, J. (1987). A taxonomy of organizational justice theories. Academy of Management review, 12(1):9-22.

Hemdi, M. A. and Nasurdin, A. M. (2007). Investigating the influence of organizational justice on hotel employees' organizational citizenship behavior intentions and turnover intentions. Journal of Human Resources in Hospitality $\mathcal{E}$ Tourism, 7(1):1-23.

Hopkins, S. M. and Weathington, B. L. (2006). The relationships between justice perceptions, trust, and employee attitudes in a downsized organization. The Journal of Psychology, 140(5):477-498.

Hubbell, A. P. and Chory-Assad, R. M. (2005). Motivating factors: Perceptions of justice and their relationship with managerial and organizational trust. Communication Studies, 56(1):47-70.

Hwang, I.-S. (2006). Dr. dan jyh-huei kuo, 2006,effects of job satisfaction and perceived alternative employment opportunities on turnover intention-an examination of public sector organizations. The Journal of American Academy of Business, Cambridge, 8.

Ingersoll, R. M. (2001). Teacher turnover and teacher shortages: An organizational analysis. American educational research journal, 38(3):499-534.

Johan, M., Talib, M., Joseph, T. M., and Mooketsag, T. L. (2013). Procedural and distributive justice on turnover intention: an exploratory analysis. Interdisciplinary journal of contemporary research in business, 4(9):182-191.

Khatri, N., Fern, C. T., and Budhwar, P. (2001). Explaining employee turnover in an asian context. Human Resource Management Journal, 11(1):54-74. 
Khattak, N. A. (2010). Customer satisfaction and awareness of islamic banking system in pakistan. African Journal of Business Management, 4(5):662.

Koslowsky, M. and Caspy, T. (1991). Stepdown analysis of variance: A refinement. Journal of Organizational Behavior, 12(6):555-559.

Lambert, E. G., Hogan, N. L., Dial, K. C., Jiang, S., and Khondaker, M. I. (2012). Is the job burning me out? an exploratory test of the job characteristics model on the emotional burnout of prison staff. The Prison Journal, 92(1):3-23.

Lehmann-Willenbrock, N., Grohmann, A., and Kauffeld, S. (2013). Promoting multifoci citizenship behavior: Timelagged effects of procedural justice, trust, and commitment. Applied Psychology, 62(3):454-485.

Li, A. and Bagger, J. (2012). Linking procedural justice to turnover intentions: A longitudinal study of the mediating effects of perceived job characteristics. Journal of Applied Social Psychology, 42(3):624-645.

Lin, C.-P. and Chen, M.-F. (2004). Career commitment as a moderator of the relationships among procedural justice, perceived organizational support, organizational commitment, and turnover intentions. Asia Pacific Management Review, 9(3):519-538.

Mobley, W. H., Griffeth, R. W., Hand, H. H., and Meglino, B. M. (1979). Review and conceptual analysis of the employee turnover process. Psychological bulletin, 86(3):493.

Mobley, W. H., Horner, S. O., and Hollingsworth, A. T. (1978). An evaluation of precursors of hospital employee turnover. Journal of Applied psychology, 63(4):408.

Moorman, R. H. (1991). Relationship between organizational justice and organizational citizenship behaviors: Do fairness perceptions influence employee citizenship? Journal of applied psychology, 76(6):845.

Neininger, A., Lehmann-Willenbrock, N., Kauffeld, S., and Henschel, A. (2010). Effects of team and organizational commitment-a longitudinal study. Journal of Vocational Behavior, 76(3):567-579.

Nunnally, J. (1978). Psychometric methods.

Pillai, R., Williams, E. S., and Justin Tan, J. (2001). Are the scales tipped in favor of procedural or distributive justice? an investigation of the us, india, germany, and hong kong (china). International Journal of Conflict Management, 12(4):312-332.

Poon, J. M. (2012). Distributive justice, procedural justice, affective commitment, and turnover intention: A mediation-moderation framework. Journal of Applied Social Psychology, 42(6):1505-1532.
Rahman, A., Naqvi, S., and Ramay, M. I. (2008). Measuring turnover intention: A study of it professionals in pakistan. International Review of Business Research Papers, 4(3):45-55.

Robinson, S. L. (1996). Trust and breach of the psychological contract. Administrative science quarterly, pages 574-599.

Rousseau, D. M., Sitkin, S. B., Burt, R. S., and Camerer, C. (1998). Not so different after all: A cross-discipline view of trust. Academy of management review, 23(3):393-404.

SPENCE LASCHINGER, H. K., Wong, C. A., Grau, A. L., Read, E. A., and PINEAU STAM, L. M. (2012). The influence of leadership practices and empowerment on canadian nurse manager outcomes. Journal of nursing management, 20(7):877-888.

Sweeney, P. D. and McFarlin, D. B. (1993). Workers evaluations of the. Organizational behavior and human decision processes, 55(1):23-40.

Tekleab, A. G., Bartol, K. M., and Liu, W. (2005). Is it pay levels or pay raises that matter to fairness and turnover? Journal of Organizational Behavior, 26(8):899-921.

Tulubas, T. and Celep, C. (2012). Effect of perceived procedural justice on faculty members silence: the mediating role of trust in supervisor. Procedia-Social and Behavioral Sciences, 47:1221-1231.

TZAFRIR, S. S., BEN-GAL, H. C., and DOLAN, S. L. (2012). 13 exploring the etiology of positive stakeholder behavior in global downsizing. Downsizing: Is less still more?, page 389.

Tzafrir, S. S., late Gedaliahu H. Harel, Baruch, Y., and Dolan, S. L. (2004). The consequences of emerging hrm practices for employees' trust in their managers. Personnel Review, 33(6):628-647.

Way, C., Gregory, D., Davis, J., Baker, N., LeFort, S., Barrett, B., and Parfrey, P. (2007). The impact of organizational culture on clinical managers' organizational commitment and turnover intentions. Journal of Nursing Administration, 37(5):235-242.

Wong, Y.-T., Wong, C.-S., and Ngo, H.-Y. (2012). The effects of trust in organisation and perceived organisational support on organisational citizenship behaviour: A test of three competing models. The International Journal of Human Resource Management, 23(2):278-293.

Zeinabadi, H. and Salehi, K. (2011). Role of procedural justice, trust, job satisfaction, and organizational commitment in organizational citizenship behavior (ocb) of teachers: Proposing a modified social exchange model. ProcediaSocial and Behavioral Sciences, 29:1472-1481. 